be managed conservatively. ${ }^{31}$ Our results suggest that not only will $16 \%$ of carcinomas be misdiagnosed but a huge burden of outpatient consultations will result if the three monthly follow up policy is adhered to. This conservative policy is also unacceptable to most patients. "

The previous policy of our unit to excise all discrete lumps occurring in the under 36 age group, whatever the preoperative diagnosis, would seem to be supported by our figures. A total of 9768 patients aged under 36 with benign breast disease were seen over the 19 years. If each of these patients had had a discrete lump and had had surgical excision the operative burden would have been 10 cases a week. Tru-Cut biopsy could be used to provide tissue provided that representative samples are obtained. Most patients, however, prefer surgical excision."

Our current policy is to perform fine needle aspiration in all women with clinically discrete breast masses. Combined ultrasonography and radiography is also performed in all patients with a discrete mass. If the results of combined mammography are equivocal compression paddle radiographs are taken. As soon as the results are available the patient is reviewed in an assessment clinic. Any concern over the nature of the mass results in excision biopsy being performed (figure).
We suggest that centres not possessing adequate cytological and combined mammographic facilities should excise all discrete breast masses in this age group without previous investigation. We also suggest that the poor detection rate by general practitioners warrants all young patients presenting with a breast lump being referred to a surgeon with an interest in breast disease.

1 Dixon JM, Anderson TJ, Lamb J. Fine needle aspiration cytology in relationship to clinical examination and mammography in the diagnosis of a solid breast mass. Br F Surg 1984;71:593-6.

2 Trott PA, Thomas MJ, Coombes RC, et al. The diagnosis of primary breast cancer in breast cancer management. London: Academic Press, 1981:1-16.

3 Wilkinson S, Forrest APM. Fibro-adenoma of the breast. Br $\mathrm{f}$ Surg $1985 ; 72: 838-40$

4 Thomas MJ, Fitzharris BM, Redding WH, et al. Clinical examination, xeromammography, and fine needle aspiration cytology in the diagnosis of

5 Smallwood J, Herbert A, Guyer PB, Taylor I. Accuracy of aspiration cytology in the diagnosis of breast disease. Brf S Surg 1985;72:841-3.

6 Ashley S, Royle GT, Corder A, et al. Clinical, radiological and cytological diagnosis of breast cancer in young women. Br f Surg 1989;76:835-7.

7 United Kingdom National Case Control Study Group. Oral contraceptive use and breast cancer risk in young women. Lancet 1989;i:973-82.

8 Teixidor HS, Kayan E. Combined mammographic-sonographic evaluation of breast masses. AfR 1977;128:409-17.

9 Warwick DJ, Smallwood JA, Guyer PB, et al. Ultrasound mammography in the management of breast cancer. Br F Surg 1988;75:243-5.

10 Cahill CJ, Boulter PS, Gibbs NM, et al. Features of mammographically negative breast cancer. Brf S Surg 1981;68:882-4.

11 Cant PJ, Madden MV, Close PM, et al. Case for conservative management of selected fibroadenomas of the breast. Brf S urg 1987;74:857-9.

(Accepted 10 January 1991)

\title{
Idiopathic first seizure in adult life: who should be treated?
}

\author{
Cees A van Donselaar, Ada T Geerts, Robert-Jan Schimsheimer
}

\section{Abstract}

Objective-To assess the accuracy of the diagnosis, recurrence rate, and fate after the first recurrence in adult patients with an untreated idiopathic first seizure.

Design-Hospital based follow up study.

Setting-One university hospital and three general hospitals in The Netherlands.

Patients - 165 patients aged 15 years or more with a clinically presumed idiopathic seizure; diagnosis was based on a description of the episode according to prespecified diagnostic criteria.

Main outcome measures-Results of additional investigations and follow up regarding the accuracy of the diagnosis; first recurrence; and response to treatment after the first recurrence.

Results-Computed tomography showed major abnormalities in $5.5 \%$ of the patients and follow up led to doubts about the initial clinical diagnosis in another $6 \%$. Cumulative risk of recurrence was $40 \%$ at two years. The cumulative risk of recurrence at two years was $81 \%$ (95\% confidence interval $66 \%$ to $97 \%$ ) in patients with epileptic discharges on a standard or partial sleep deprivation electroencephalogram, $39 \%(27 \%$ to $51 \%)$ in patients with other electroencephalographic abnormalities, and $12 \%(3 \%$ to $21 \%$ ) in patients with normal electroencephalograms. Treatment was initiated in most patients who had one or more recurrences; $40(70 \%)$ patients were completely controlled, eight $(14 \%)$ had sporadic seizures, and nine $(16 \%)$ did not become free of seizures within one year despite treatment

Conclusions-The decision to initiate or delay treatment should be based on electroencephalographic findings.

\section{Introduction}

Opinions differ on the treatment of patients with an idiopathic first seizure. ${ }^{1-4}$ Treating all patients immediately reduces the number of recurrences 5 and might reduce the number of patients with intractable disease in the long term. ${ }^{67}$ This policy might mean, however, that many patients would be treated unnecessarily.

The data required to solve this dilemma are either lacking or a matter of dispute. The reliability and accuracy of the diagnosis of a first seizure are not known,${ }^{8}$ and investigations of the recurrence rate have produced widely diverging results. ${ }^{9-15}$ The fate of patients after the first recurrence has not been investigated. We conducted a hospital based investigation of 165 patients aged 15 years or more with an idiopathic untreated first seizure.

\section{Patients and methods}

We prospectively studied all patients aged 15 years or more with a presumed idiopathic first seizure who were referred to one university hospital and three general hospitals during March 1986 to March 1988 Patients who had had a seizure other than febrile convulsions in the past were excluded, as were patients presenting with a status epilepticus or with a seizure that had lasted more than 30 minutes. We admitted only patients in whom there was no obvious clinical cause for the seizure. ${ }^{16}$ Patients with seizures that may have been induced by sleep deprivation or stress were included, except for those who had experienced extreme conditions such as not sleeping for several days.

The diagnosis was based on the description of the episode according to prespecified diagnostic criteria, ${ }^{8}$ the medical history, and the neurological examination. We previously showed that the reliability of these criteria was good $(x=0.73){ }^{8}$ All patients were discussed by three neurologists before admission.

The four centres referred 226 patients, and 61 were excluded: four because they did not attend for additional investigations and 57 because another
Correspondence to:

BMF 1991;302:620-3 
condition was diagnosed. Presumed idiopathic first seizure was diagnosed in the remaining 165. The patients (97 men and 68 women; mean age 38 years (range 15-85 years)) had all been unconscious with repetitive myoclonic jerks (52), stiffening (eight), tongue biting (seven), or a combination of these symptoms (95); one patient had had a simple partial seizure and two had had complex partial seizures. Generalised seizures were not subclassified as the reliability and accuracy of such classification is too poor to be clinically useful..$^{17} 18$

Eighty seven (53\%) patients were seen within 24 hours after the seizure, 115 (70\%) within one week, 137 $(83 \%)$ within two weeks, and $155(94 \%)$ within one month; all were seen within three months, and the mean time after seizure was 6.7 days. An electrocardiogram and blood samples were obtained for all patients and a computed tomogram for 162 patients.

For analysis of the recurrence rates we excluded nine patients who had major abnormalities on computed tomography, three patients who had a second seizure within 24 hours after the first, and two patients who were treated immediately with antiepileptic drugs. Standard electroencephalography was done in the remaining 151 patients. If the first electroencephalogram did not show epileptic discharges (spikes or spikewave complexes) electroencephalography was repeated after partial sleep deprivation in all but three eligible patients. All the electroencephalograms were read by one neurologist (RJS), who had no access to the clinical information, and rated as normal, showing epileptic discharges, or showing other abnormalities. (Details of the registration of the electroencephalograms, the protocol used for the visual interpretation, and the interobserver agreement $(x=0.50$ for the occurrence of epileptic discharges) are available from us).

Length of follow up was determined by time of admission and ranged from one to two years. One patient was lost to follow up after one month and another after 20 months. Patients who had recurrences were followed up for one additional year. We used survival analysis techniques (Kaplan-Meier). ${ }^{19}$ The two patients who were lost to follow up were included in the analysis.

\section{Results}

\section{ACCURACY OF DIAGNOSIS}

The reasons for excluding referred patients were as follows. Hyperventilation and migraine were each diagnosed in one patient. Follow up of these patients for one year gave no reason to doubt these diagnoses. In 24 patients the episodes were clinically classified as acute or remote symptomatic seizures, half of which were supposed to be due to alcohol misuse. Additional investigations such as tests of liver function confirmed the diagnoses as far as possible in all but one patient (known to have lung cancer), in whom computed tomography did not show the expected metastases.

Syncope with myoclonic jerks was diagnosed in seven patients. Neither electroencephalography nor follow up for one year contradicted this diagnosis. Twenty four patients were excluded as the description of their seizures did not fulfil our criteria, although no other condition was diagnosed. Cardiac arrhythmias were found in one patient. Three patients had further seizures but epilepsy could not be firmly diagnosed.

Among the patients eligible for the study computed tomography showed the clinical diagnosis of an idiopathic seizure to be false in nine $(5 \cdot 5 \%, 95 \%$ confidence interval $2 \%$ to $9 \%$ ), the scans showing arteriovenous malformation (one patient), metastases (one), brain tumours (four), arachnoidal cyst (one), and infarction (two). Focal atrophies were found in six patients, which we regarded as clinically irrelevant. A transient hypodensity (vanishing tumour) was found in one patient who had a second seizure within 24 hours.

Follow up suggested that the initial diagnosis could have been wrong in an additional 10 patients $(95 \%$ confidence interval $2 \%$ to $10 \%$ ). One patient developed a psychogenic hemiplegia shortly after her first seizure. Four patients (including the patient with the arteriovenous malformation) were suspected to be misusing alcohol, and we discovered afterwards that one patient had discontinued prolonged use of mild tranquillisers two days before the seizure. One patient, who had a seizure accompanied by postictal paresis and had normal results on computed tomography, was later diagnosed as having had an infarction on the basis of a second computed tomogram taken after a second, identical seizure. Three patients were found to have cardiac arrhythmias that might have caused the seizures.

One other patient aged 17, who was admitted because of a nocturnal generalised seizure, suddenly died 12 months later. After her first seizure she complained a few times about episodes of feeling dizzy without clear provocative conditions. A few weeks before her death she had nearly fainted on two occasions after an unexpected sound. In retrospect, the initial electrocardiogram showed a prolonged QT interval, indicating that she probably had the prolonged QT syndrome. The syndrome might have caused her first seizure, but this cannot be proved.

\section{RISK OF RECURRENCE}

The overall recurrence rate for the 151 patients with an idiopathic, untreated, isolated seizure (confirmed by computed tomography) was $40 \%$ ( $95 \%$ confidence interval $32 \%$ to $48 \%$ ) at two years (fig). Three patients presented with status epilepticus as "second" seizure. None of the second seizures caused serious morbidity. Four patients died of cardiac arrhythmia, myocardial infarction, lung cancer without intracerebral metastases, and leukaemia.

Table I shows the predictive factors for a second seizure. Higher recurrence rates were associated with younger age, occurrence of first seizure during sleep or on awakening, and tongue biting. Family history, provocative circumstances, and sex did not correlate significantly with the risk of recurrence. Association of the recurrence rate with the interval between first seizure and first visit to the hospital was inconsistent.

The standard electroencephalogram showed epileptic discharges in 16 patients, of whom 15 experienced a second seizure within two years (one patient remained

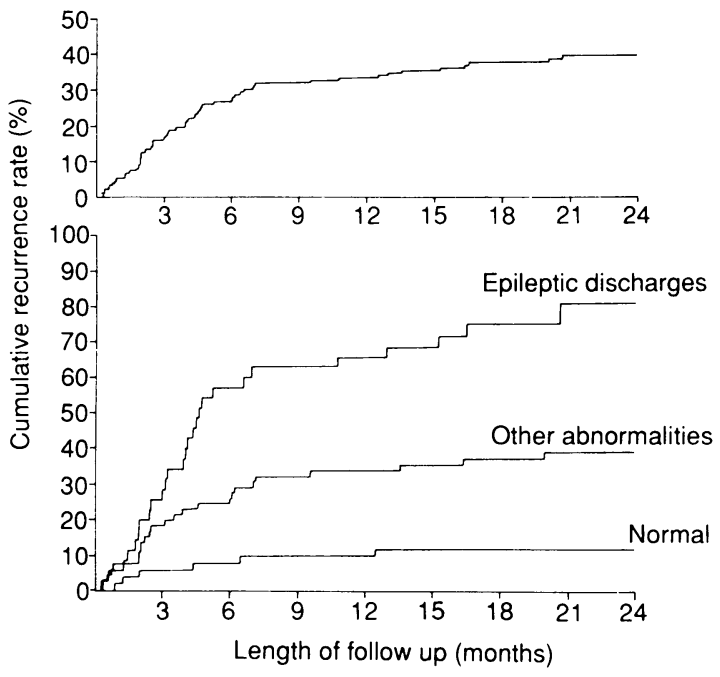

Continuously adjusted recurrence rates in patients with idiopathic first seizures: (top) all patients, (bottom) according to electroencephalographic findings 


\begin{tabular}{|c|c|c|c|}
\hline Predictive factor & $\begin{array}{l}\text { No of patients } \\
\quad(n=151)\end{array}$ & $\begin{array}{l}\text { Recurrence rate at } 2 \text { years }(\%) \\
(95 \% \text { confidence interval })\end{array}$ & $\begin{array}{l}\text { Observed difference }(\%) \\
(95 \% \text { confidence interval) }\end{array}$ \\
\hline \multicolumn{4}{|l|}{ Age: } \\
\hline $15-24$ & 50 & $50(36$ to 64$)$ & $11(-9 \text { to } 31)^{\star}$ \\
\hline $25-44$ & 52 & 39 (25 to 43 ) & $10(-9$ to 29$) t$ \\
\hline $45-85$ & 49 & $29(16$ to 42$)$ & $21(2$ to 40$)$ \\
\hline \multicolumn{4}{|l|}{ Family history $§:$} \\
\hline Negative & 133 & $40(31$ to 49$)$ & $4(-22$ to 30$) \neq$ \\
\hline Positive & 16 & $44(20$ to 68$)$ & \\
\hline \multicolumn{4}{|c|}{$\begin{array}{l}\text { Interval between first seizure and } \\
\text { first visit: }\end{array}$} \\
\hline$<24$ Hours & 77 & $31(20$ to 42$)$ & $22(4 \text { to } 40)^{\star}$ \\
\hline 1-14 Days & 54 & $53(39$ to 67$)$ & $18(-7$ to 43$) \dagger$ \\
\hline$>14$ days & 20 & $35(14$ to 56$)$ & $4(-20$ to 28$) \neq$ \\
\hline \multicolumn{4}{|l|}{ Time of occurrence: } \\
\hline During day & 118 & $32(23$ to 41$)$ & $40(20$ to 60$)$ \\
\hline While asleep or awakening & 33 & $72(54$ to 90$)$ & \\
\hline \multicolumn{4}{|l|}{ Provocative circumstances: } \\
\hline Absent & 100 & $44(34$ to 54$)$ & $12(-5$ to 29$)$ \\
\hline Present & 51 & $32(19$ to 45$)$ & \\
\hline \multicolumn{4}{|l|}{ Standard electroencephalogram: } \\
\hline Epileptic discharges & 16 & $100(70$ to 100$)$ & $60(40 \text { to } 80)^{\star}$ \\
\hline Other abnormalities & 68 & $40(29$ to 52$)$ & $15(-1$ to 31$) \dagger$ \\
\hline Normal & 67 & $25(14$ to 36$)$ & $75(55$ to 95$) \ddagger$ \\
\hline \multicolumn{4}{|c|}{$\begin{array}{l}\text { Combined results of standard sleep } \\
\text { deprivation electroencephalograms: }\end{array}$} \\
\hline Epileptic discharges & 35 & 81 (66 to 97$)$ & $42(22 \text { to } 62)^{\star}$ \\
\hline Other abnormalities & 65 & $39(27$ to 51$)$ & $27(12$ to 42$) \dagger$ \\
\hline Normal & 51 & $12(3$ to 21$)$ & $69(51$ to 87$) \ddagger$ \\
\hline \multicolumn{4}{|l|}{ Tongue biteł: } \\
\hline Absent & 81 & 27 (17 to 37$)$ & 28 (12 to 44$)$ \\
\hline Present & 70 & 55 ( 43 to 67$)$ & \\
\hline \multicolumn{4}{|l|}{ Sex: } \\
\hline Male & 91 & 35 ( 25 to 45$)$ & $12(-5$ to 29$)$ \\
\hline Female & 60 & $47(34$ to 60$)$ & \\
\hline
\end{tabular}

^First group minus second group. †Second group minus third group. $\ddagger$ First group minus third group. $§$ No data available on two patients. free of seizures during the scheduled follow up period of 16 months; cumulative risk of recurrence at two years was $100 \%(70 \%$ to $100 \%))$. The cumulative recurrence rate was $40 \%$ (29\% to $52 \%)$ in 68 patients with non-epileptic abnormalities and $25 \%$ (14\% to $36 \%)$ in 67 patients with normal findings. Electroencephalography performed after sleep deprivation identified 19 additional patients with epileptic discharges, 12 of whom relapsed. Table II shows the predictive value of the combined electroencephalograms. Standard and combined electroencephalograms identified $26 \%$ (15\% to $39 \%$ ) and $47 \%$ (34\% to $59 \%$ ) of those who had recurrences respectively. The specificity of electroencephalography was $99 \%(94 \%$ to $100 \%)$ for standard conditions and $91 \%(86 \%$ to $97 \%)$ for the combined electroencephalograms.

\section{OUTCOME}

To analyse the outcome in the 58 patients with an idiopathic first seizure who had a recurrence we excluded one patient who refused drugs despite several recurrences. Forty $(70 \%)$ patients became free of seizures, eight (14\%) had sporadic seizures (one or two during twelve months after a titration period of two months), and nine (16\%) continued to have seizures despite taking drugs during one year follow up. One of the electroencephalograms had shown epileptic discharges in 10 out of the 17 patients who continued to have seizures, and both electroencephalograms had been normal in one patient; non-epileptic abnormalities were found in six patients.
Twenty five patients were started on drugs immediately after their first recurrence. Treatment was postponed until more recurrences had occurred in 26 patients, and six patients were given no drugs and had no further recurrences. Retrospectively, the decision to start or postpone treatment after the first recurrence seemed to have been made at random in most patients. Mean interval between first seizure and first recurrence was about equal in both groups. The outcome was better in patients treated early (excluding the three patients who had status epilepticus as second seizures) than in those whose treatment was postponed (19 $(86 \%)$ v $20(63 \%)$ free of seizures $(95 \%$ confidence interval of difference $2 \%$ to $46 \%$ ); one (5\%) $v$ seven $(22 \%)$ had sporadic seizures $(0 \%$ to $34 \%)$; two $(9 \%) v$ five $(16 \%)$ continued to have seizures $(-11 \%$ to $24 \%)$ ).

\section{Discussion}

The diagnosis of a first seizure is often difficult. Other studies have not mentioned the diagnostic criteria ${ }^{9-11131520}$ or have used the international classification of seizures, ${ }^{12}{ }^{1421}$ which provides only guidelines for classification once a seizure has been diagnosed. To enhance the consistency of recruitment we used simple descriptive diagnostic criteria with verified reliability. ${ }^{8}$

Computed tomography showed the initial clinical diagnosis to be wrong in $5.5 \%$ of the patients, and this figure agrees with the findings of another Western study. ${ }^{15}$ We believe that this error is sufficiently high to warrant this additional investigation, but we realise that we live in a prosperous country. Follow up led to the initial clinical diagnosis being doubted in an additional $6 \%$. This does not mean that all other admitted patients had indeed had an idiopathic seizure as an objective test is lacking. Only one other study has mentioned any patient in whom the initial diagnosis proved to be wrong. ${ }^{9}$

We believe that the diagnostic criteria were sufficiently reliable and accurate to allow decisions such as initiating antiepileptic drugs to be made. Doctors should beware, however, of cardiac arrhythmias even in young people. ${ }^{22}$

We classified seizures that were possibly provoked by sleep deprivation or stress as idiopathic. The presence of such circumstances was associated with slightly lowered risk of recurrence, and thus attributing first seizures solely to provocative circumstances could lead to false reassurance.

Our recurrence rate of $40 \%$ at two years agrees with the results of Hopkins $e t a l$, who found a recurrence rate of $45 \%$ (including $4 \%$ patients with abnormalities on computed tomography). ${ }^{15}$ Lower recurrence rates were found in American studies, in which most patients were treated immediately with antiepileptic drugs. ${ }^{1214}$ Moreover, intervals between the first seizure and admission into these studies were not stated. The longer the waiting period the more chance that patients had already had a relapse.? This may have led to bias

TABLE II-Cumulative recurrence rates based on findings in combined standard and sleep deprivation electroencephalograms in 151 patients with idiopathic first seizures

\begin{tabular}{|c|c|c|c|c|c|c|c|c|c|c|c|c|}
\hline \multirow[b]{2}{*}{ Month } & \multicolumn{3}{|c|}{ Epileptic discharge } & \multicolumn{3}{|c|}{ Other abnormalities } & \multicolumn{3}{|c|}{ Normal } & \multicolumn{3}{|c|}{ All patients } \\
\hline & $\begin{array}{c}\text { Recurrence } \\
\text { rate }(\%) \\
(95 \% \\
\text { confidence } \\
\text { interval })\end{array}$ & $\begin{array}{l}\text { No at } \\
\text { risk }\end{array}$ & $\begin{array}{l}\text { No who had } \\
\text { had } \\
\text { recurrences } \\
\text { (No } \\
\text { censored }\end{array}$ & $\begin{array}{c}\text { Recurrence } \\
\text { rate }(\%) \\
(95 \% \\
\text { confidence } \\
\text { interval) }\end{array}$ & $\begin{array}{l}\text { No at } \\
\text { risk }\end{array}$ & $\begin{array}{l}\text { No who had } \\
\text { had } \\
\text { recurrence } \\
(\text { No } \\
\left.\text { censored }^{\star}\right)\end{array}$ & $\begin{array}{c}\text { Recurrence } \\
\text { rate }(\%) \\
(95 \% \\
\text { confidence } \\
\text { interval })\end{array}$ & $\begin{array}{l}\text { No at } \\
\text { risk }\end{array}$ & $\begin{array}{c}\text { No who had } \\
\text { had } \\
\text { recurrence } \\
\text { (No } \\
\text { censored }^{\star} \text { ) }\end{array}$ & $\begin{array}{l}\text { Recurrence } \\
\text { rate }(\%) \\
(95 \% \\
\text { confidence } \\
\text { interval })\end{array}$ & $\begin{array}{c}\text { No at } \\
\text { risk }\end{array}$ & $\begin{array}{l}\text { No who had } \\
\text { had } \\
\text { recurrence } \\
\text { (No } \\
\text { censored }\end{array}$ \\
\hline 0 & & 35 & & & 65 & & & 51 & & & 151 & \\
\hline 6 & $57(41$ to 74$)$ & 15 & 20 & $26(16$ to 37$)$ & 48 & 17 & $8(1$ to 15$)$ & 46 & $4(1)$ & $27(20$ to 34$)$ & 109 & $41(1)$ \\
\hline 12 & 66 (50 to 81$)$ & 12 & 3 & 34 ( 22 to 45 ) & 43 & 5 & $10(2$ to 18$)$ & 45 & 1 & 33 (26 to 41$)$ & 100 & 9 \\
\hline 18 & $75(61$ to 90$)$ & 7 & $3(2)$ & $37(25$ to 49$)$ & 35 & $2(6)$ & $12(3$ to 21$)$ & 31 & $1(13)$ & $38(30$ to 46$)$ & 73 & $6(21)$ \\
\hline 24 & $81(66$ to 97$)$ & 2 & $1(4)$ & $39(27$ to 51$)$ & 23 & $1(11)$ & $12(3$ to 21$)$ & 13 & (18) & $40(32$ to 48$)$ & 38 & $2(33)$ \\
\hline
\end{tabular}

$\star$ Not all patients were scheduled for follow up of two years. 
towards including patients with a more favourable prognosis.

Elwes et al found a recurrence rate of $69 \%$ at two years. ${ }^{13}$ This study proved to be partly prospective and partly retrospective,,$^{23}$ and idiopathic, remote symptomatic, and acute symptomatic seizures were considered together. In addition, patients with seizures recurring within 24 hours were included. We believe that these patients should not be taken into account as immediate treatment will not prevent early recurrences.

Hart et al reported a risk of recurrence of $78 \%$ at three years. ${ }^{24}$ The clinical applicability of these findings is difficult to assess. An epileptic seizure disorder was diagnosed six months after the index seizure after examining all available information, including the recurrence pattern. Moreover, more than half the patients had already had a second seizure at entrance into the study.

The first year of treatment is crucial for the long term prognosis. ${ }^{2527}$ We found that $17(30 \%)$ of the patients who had a second seizure $(11 \%$ of the original 151 patients) did not become completely free of seizures within one year. This agrees with former studies on the prognosis of newly treated patients with epilepsy..$^{2527: 32}$

If all patients were treated immediately after their first seizure intractability might be prevented in some patients. Elwes et al found that the interval between untreated seizures decreased successively and that the number of seizures before treatment was started correlated with the outcome of treatment. ${ }^{27}{ }^{33} \mathrm{We}$ also found that delaying treatment until more than one recurrence had occurred resulted in poorer outcome, but the number of patients was small and our patients were not randomised.

Even if immediate treatment would halve the number of patients who do not become free of seizures (from $11 \cdot 0 \%$ to $5 \cdot 5 \%$ ), which seems to us rather optimistic, the effect of unnecessary treatment in those patients who would not have a second seizure without drugs ( $60 \%$ of the study population) has to be balanced. An alternative approach is to take into account the electroencephalographic findings. We found that epileptic discharges were associated with a highly increased risk of recurrence. Immediate treatment of these patients would reduce the number who would be treated unnecessarily. In these patients the benefits of drugs probably counterbalance the disadvantages.

The risk of recurrence if both electroencephalograms appeared normal was low. Only one of the 51 patients had sporadic seizures despite drugs, and all others who eventually had recurrences became free of seizures. Clearly, it is unwise to initiate treatment in these patients. The $39 \%$ risk of recurrence in patients with non-epileptic abnormalities also seems to be too low to warrant immediate treatment.

The reliability of visual interpretation of electroencephalograms is moderate. On the other hand, most other studies have shown an increased risk of recurrence in patients with electroencephalographic abnormalities. ${ }^{11} 1214$
We thank the following neurologists for their cooperation: H A W Sinnige, J A G Strijbosch, H J van der Brand, G van Woerkom (St Clara Hospital, Rotterdam); A de Weert, J Jonkman, L Laan, W F Arts, W V M Perquin (Westeinde Hospital, The Hague); P R Beneder, C Bulens, L H Penning de Vries (St Franciscus Hospital, Rotterdam). This project was supported by the TNO research committee on epilepsy (project number CLEO A-57).

1 Hauser WA. Should people be treated after a first seizure? Arch Neurol 1986; $43: 1287-8$

2 Hart RG, Easton JD. Seizure recurrence after a first, unprovoked seizure. Arch Neurol 1986;43:1289-90.

3 Hachinski V. Management of first seizure. Arch Neurol 1986;43:1290.

4 Holmes GL. How to evaluate the patient after a first seizure. Postgrad Med 1988;83:199-209.

5 Camfield PR, Camfield CS, Dooley J, Smith E, Garner B. A randomised study of carbamazepine versus no medication after a first unprovoked seizure in childhood. Neurology 1989;39:851-2.

6 Reynolds EH. Early treatment and prognosis of epilepsy. Epilepsia 1987;28: 97-106.

7 Reynolds EH, Elwes RDC, Shorvon SD. Why does epilepsy become intractable? Prevention of chronic epilepsy. Lancet 1983;ii:952-4.

8 Donselaar CA van, Geerts AT, Meulstee J, Habbema JDF, Staal A. Reliability of the diagnosis of a first seizure. Neurology 1989;39:267-71.

9 Johnson LC, DeBolt WL, Long MT, et al. Diagnostic factors in adult males following initial seizures. Arch Neurol 1972;27:193-7.

10 Saunders M, Marshall C. Isolated seizures: an EEG and clinical assessment. Epilepsia 1975;16:731-3.

11 Cleland PG, Mosqauera I, Steward WP, Foster JB. Prognosis of isolated seizures in adult life. $B M \mathcal{J} 1981 ; 283: 1364$

12 Hauser WA, Anderson VE, Loewenson RB, McRoberts SM. Seizure recurrence after a first unprovoked seizure. $N$ Engl F Med 1982:307:522-8.

13 Elwes RDC, Chesterman P, Reynolds EH. Prognosis after a first untreated tonic-clonic seizure. Lancet 1985;ii:752-3.

14 Annegers JF, Shirts SB, Hauser WA, Kurland LT. Risk of recurrence after an initial unprovoked seizure. Epilepsia 1986;27:43-50.

15 Hopkins A, Garman A, Clarke C. The first seizure in adult life. Value of clinical features, electroencephalography, and computerised tomographic clinical features, electroencephalography, and computerised to

16 Hauser WA, Kurland LT. The epidemiology of epilepsy in Rochester, Minnesota, 1935 through 1967. Epilepsia 1975;16:1-66.

17 Bodensteiner JB, Brownsworth RD, Knapik JR, Kanter MC, Cowan LD Leviton A. Interobserver variability in the ILAE classification of seizures in childhood. Epilepsia 1988;29:123-8.

18 Donselaar CA van, Geerts AT, Schimsheimer RJ. Usefulness of an aura for the classification of a first generalized seizure. Epilepsia 1990;31:529-35.

19 Biomedical Programs Data Package. Statistical software. Berkeley: University of California Press, 1981

20 Thomas MH. The single seizure: its study and management. FAMA 1959;169: 457-9.

21 Commission on classification and terminology of the International League against Epilepsy. Proposal for revised clinical and electroencephalographic classifications of epileptic seizures. Epilepsia 1981;22:489-501.

22 Schot GD, McLeod AA, Jewitt DE. Cardiac arrhythmias that masquerade as epilepsy. $B M \mathcal{F}^{1977 ; \text {; }: 1454-7 .}$

23 Elwes RDC, Reynolds EH. First seizure in adult life. Lancet 1988;ii: 36.

24 Hart YM, Sander JWAS, Johnson AL, Shorvon SD. National general practice study of epilepsy: recurrence after a first seizure. Lancet 1990;336:1271-4.

25 Shorvon SD, Reynolds EH. Early prognosis of epilepsy. BMF 1982:285:1699701

26 Shorvon SD. The temporal aspects of prognosis in epilepsy. $f$ Neurol Neurosurg Psychiatry 1984;47:1157-65.

27 Elwes RDC, Johnson AL, Shorvon SD, Reynolds EH. The prognosis for seizure control in newly diagnosed epilepsy. $N$ Engl f Med 1984;311:944-7.

28 Luhdorf K, Jensen LK, Plesner AM. Epilepsy in the elderly: prognosis. Acto Neurol Scand 1986;74:409-15.

29 Mattson RH, Cramer JA, Collins JF, et al. Comparison of carbamazepine, phenobarbital, phenytoin, and primidone in partial and secondarily generalized tonic-clonic seizures. $N$ Engl f Med 1985;313:145-51

30 Turnbull DM, Howel D, Rawlins MD, Chadwick DW. Which drug for the adult epileptic patient: phenytoin or valproate? $B M \mathcal{F}$ 1985;290:815-9.

31 Ramsay RE, Wilder BJ, Berger JR, Bruni J. A double-blind study comparing carbamazepine with phenytoin as initial seizure therapy in adults. Neurology 1983;33:904-10.

32 Callaghan N, Kenny RA, O'Neill B, Crowley M, Goggin T. A prospective study between carbamazepine, phenytoin and sodium valproate as monotherapy in previously untreated and recently diagnosed patients with epilepsy. I Neurol Neurosurg Psychiatry 1985;48:639-44.

33 Elwes RDC, Johnson AL, Reynolds EH. The course of untreated epilepsy. BMF 1988;47:620-2.

(Accepted 7 fanuary 1991)

\section{ONE HUNDRED YEARS AGO}

In the British Medical Journal of January 24th, reference was made to a letter on the value of Greek and Latin as educational agents, which Professor J. Stuart Blackie had published elsewhere. It was pointed out that he appeared to reserve his opinion as to the desirability of making Greek and Latin, or Latin alone, compulsory parts of the medical curriculum. We have since received from Professor Blackie the following letter, in which he briefly discusses the subject: "Dear Sir, - My decided opinion is that one ancient and one modern language should be demanded of all who take honours in any of the learned professions. For law, I should say Latin and German; for medicine, Greek and German; and for theology, Greek and German. But at the same time I am quite willing to give the candidate an option, so that instead of Greek he might take Latin; and instead of German, French or Italian, or even Spanish; but what I would insist on is that the languages should be known thoroughly and practically, and not in the way of cram for examination purposes. - Sincerely yours, JOH. S. BLACKIE."(British Medical Fournal 1891;i:245) 